Immunonkologie

\title{
Prädiktive Biomarker für die Patientenselektion
}

Das adaptive Immunsystem gilt heute als "ideale" Antitumortherapie, da mit T-Zellen und Antikörpern eine hohe Diversität gegeben ist, das Immunsystem kleinste chemische Alterationen unterscheidet und nach einem effektiven Antigen-Priming eine nachhaltige Wirkung erzielt wird. T-Zellen sind ideale Tumorkiller, sagte Prof. Andrea Tannapfel, Bochum, auf dem DKK in einer Keynote-Lecture.

Die derzeit erfolgreichste Strategie der immunonkologischen Therapie ist die PD-1-/PDL1-Blockade durch Checkpoint-Inhibitoren. PD-1 ist ein Rezeptor, der auf der Oberfläche von T-Zellen exprimiert wird. PD-L1, ein Ligand des PD-1-Rezeptors wird in rund $30 \%$ aller soliden Tumoren exprimiert, so etwa beim Melanom in 40 bis $100 \%$ der Fälle und beim NSCLC in 35 bis $95 \%$ der Fälle (1). Ob PD-L1 ein guter Biomarker sein könnte, wäre auch eine Frage des passenden Antikörpers, konstatierte Tannapfel. Sie verwies darauf, dass in rund $20 \%$ der Fälle eine heterogene Positivität mit diskordanten Ergebnissen bei Primärtumor und Metastasen beobachtet wurde (2). Die Metastasen sollten daher auch auf ihre PD-1-/PDL1-Exprimierung analysiert werden.

Damit muss auch die Frage gestellt werden, was einen guten Biomarker eigentlich ausmacht, bemerkte Tannapfel. Sie erwartet von einem guten Biomarker, dass

- Konsistenz in mehreren randomisierten prospektiven Studien und Methoden besteht,

- er leicht und schnell analysierbar sowie biologisch plausibel ist. 
- er eine „ja” oder „nein"-Antwort für die Patientenselektion möglich macht und in Primärtumor und Metastase gleichermaBen anwendbar ist.

Für die PD-L1-Expression konnte nur beim Lungenkarzinom Biomarkerqualität gezeigt werden. Mit der Immunhistochemie liegt ein einfacher Test vor, aber es werden unterschiedliche Antikörper und Grenzwerte verwendet. PD-L1 ist als Biomarker biologisch plausibel, aber die Patientenselektion ist nicht eindeutig möglich, sondern nur relativ mit Grenzwerten und Zonierungen schätzbar.

Eine vielversprechende Strategie für die Prädiktion eines Ansprechens auf die Immuntherapie ist die Messung der Tumormutationslast (TMB). Liegen viele Mutationen vor, so gibt es auch viele Neoantigene, die vom Immunsystem erkannt und bekämpft werden können. Die Entitäten mit der höchsten somatischen Mutationslast sind das Melanom und das Lungenkarzinom. Es wurde für diese beiden Entitäten, wie auch für das Ovarialkarzi- nom, das Prostatakarzinom und das Kolonkarzinom (bei hoher Mikrosatelliteninstabilität, MSI-H), eine Korrelation der hohen TMB mit einer guten Prognose und einem guten Ansprechen auf die Checkpoint-Blockade gezeigt.

Die Machbarkeit der pathologischen Messung der Mutationslast sei derzeit noch etwas kompliziert, erklärte Tannapfel, da entweder das aufwendige Whole-Exom-Sequencing (WES) durchgeführt werden muss oder neue Panels eingesetzt werden, die allerdings derzeit noch nicht in der Praxis angekommen sind. Der Umweg über die Messung der MSI ist nicht möglich, so Tannapfel, da auch bei Mikrosatelliten-stabilen Tumoren erhöhte Mutationslast gefunden wurde und MSI und TMB somit nicht gleichzusetzen seien. In einer Studie mit 2013 Kolorektalkarzinompatienten, die simultan auf MSI und TMB getestet wurden, zeigte sich eine hohe Mutationslast bei allen MSI-H Patienten 3,5\%) (3). Allerdings hatten 424 Patienten (21,9\%) mit Mikrosatellitenstabilität (MSS) ebenfalls eine hohe TMB. Ob MSI oder TMB der bessere Biomarker sei, bleibe abzuwarten, so Tannapfel. Sie erwarte aber, dass die Tumormutationslast als prädiktiver Biomarker sehr wahrscheinlich kommen werde.

Dr. Ine Schmale, Westerburg

\section{Literatur}

1. Chen DS et al. Molecular pathways: Next-generation immunotherapy - inhibiting programmed death-ligand 1 and programmed death-1. Clin Cancer Res 2012; 18: 6580-6587.

2. Callea $\mathrm{M}$ et al. Differential expressoin of PD-L1 between primary and metastatic sites in clear cell renal cell carcinoma. Cancer Immunol Res 2015; 3: 1158-1164.

3. Alexandrov LB et al. Signatures of mutional processes in human cancer. Nature 2013; 500: 415-421.

4. George TJ et al. Tumor mutational burden as a potential biomarker for PD1/PD-L1 therapy in colorectal cancer. ASCO 2016, Abstract 3587.

Quelle: AIO-Symposium „Immunonkologie 2018 Standards und neue Ansätze" im Rahmen des Deutschen Krebskongresses (DKK) am 21. Februar 2018, Berlin. 